\title{
Apurados os 27 Finalistas da EdiçÃo de 2009 das "Olimpíadas de Química"
}

Já estão apurados os finalistas das "Olimpíadas de Química+2009", após a competição que decorreu em Aveiro, Porto e Lisboa no passado dia 14 de Março.

A edição de 2009 voltou a registar um significativo aumento de escolas participantes, tendo sido a mais participada de sempre.

Com 124 Escolas inscritas, esta edição superou largamente os números dos anos anteriores (76 Escolas em 2006, 94 Escolas em 2007, 106 Escolas em 2008).

A acolher estes participantes estiveram as equipas coordenadas pela Prof. Diana Pinto (Semifinal de Aveiro), Prof. Jorge Gonçalves (Semifinal do Porto) e Prof. Jorge Morgado (Semifinal de Lisboa).

A todos os que contribuíram para o sucesso desta iniciativa a Direcção da SPQ expressa o seu agradecimento.

Os 27 alunos agora apurados vão disputar a Final nacional, a realizar no Departamento de Química da Universidade de Aveiro, a 9 de Maio, numa competição individual que inclui uma prova teórica e uma prova prática laboratorial.

$$
* * * \text { LISTA DOS VENCEDORES } * * *
$$

Semifinal de Aveiro (Departamento de Química, Universidade de Aveiro)

Medalhas de Ouro

ES de Homem Cristo

Marta Cristina Neves Aguiar

Daniel Martins

Pedro Jorge Vieira

Professor: Maria Fernanda Quinta e Dulcina Carvalho

Medalhas de Prata

ES/B3 de Peniche

Alexandre Faia Carvalho

Maria de Azevedo António Machado da Silva

Geisa Silva Félix

Professor: Maria Leonor Chagas

Marques e Manuel Lopes Martins

Medalhas de Bronze

ES de Francisco Rodrigues Lobo

André Guarda

Gonçalo Filipe Moura Ferreira

João Carlos Marques

Professor: Maria Amélia Moura

Semifinal do Porto (Departamento de Química, Universidade do Porto)

Medalhas de Ouro

Colégio Internato dos Carvalhos

Bruno Tiago Lopes Carneiro Devesa

Bianca Andrada Rosca

Diogo André Gonçalves Domingues

Professor: Maria Manuela Raposo Martins
Medalhas de Prata

ES/B3 Rio Tinto

Sérgio Marcos

Paulo Rúben Gomes Fernandes

Rodrigues

Marília dos Santos Lima

Professor: Manuel César Gaspar Fecha

Medalhas de Bronze

ES/B3 Emídio Garcia - Bragança

Jorge Pedro Martins Nogueiro

Liane Canas

Fábio Sousa Cruz

Professor: Inês Madaleno

Semifinal de Lisboa (Instituto Superior Técnico, Universidade Técnica de Lisboa)

Medalhas de Ouro

ES José Saramago - Mafra

Alexandra Castelo

Bianca Rosca

Gonçalo Bonifácio

Medalhas de Prata

ES Pinheiro e Rosa - Faro

Joana Isabel Afonso

Ana Catarina

Rafael Vieira

Medalhas de Bronze

ES Bocage - Setúbal

Carla Viegas

Delfim Costa

Marta Fidalgo

\section{EYCN: European Young Chemists Network}

A European Young Chemists Network (EYCN) continua a crescer, contando actualmente com 21 sociedades de química europeias, incluindo o seu associado mais recente, a Swedish Chemical Society. Qualquer membro das Sociedades de Química Europeias associadas, incluindo a SPQ, que tenha menos de 35 anos, pertence por direito a esta rede. Poderá informar- -se com mais detalhe das suas actividades em: http://www.eycn.eu/

Durante a quarta reunião de delegados da EYCN que se realizou em Essen (Alemanha) no dia 11 de Março de 2009, na qual o Grupo de Químicos Jovens (GQJ) da Sociedade Portuguesa de Química (SPQ) se fez representar, discutiu-se uma série de pontos que queremos partilhar com os restantes químicos jovens portugueses:

ResearchGate: existe uma rede profissional virtual para cientistas desenhada de forma a facilitar o seu encontro (https://www.researchgate. net/), onde os seus membros podem comunicar e discutir ideias. Foi criado um grupo dentro desta plataforma para a EYCN:

https://www.researchgate.net/group/ Friends_of_EYCN

Chemistry Eurobachelor e Chemistry Euromaster: de forma a facilitar a mobilidade de Químicos entre países da União Europeia, têm-se vindo a conceder "Chemistry Quality Labels" a cursos ( $1^{\circ}$ e $2^{\circ}$ ciclo de Bolonha) que reconhecem a paridade destes em termos de qualidade da formação oferecida. A lista de cursos em Química abrangidos por estas "Labels" pode ser consultada no seguinte link:

http://ectn-assoc.cpe.fr/chemistry-eurolabels/srvc/cel_LabelsAwarded_NatInst.htm

Conferências para Químicos Jovens na Europa

- JFC Spring Symposium. O grupo de Jovens Químicos Alemães (GDCh Younger Chemists' Forum) organizou a $11^{a}$ edição deste evento que decorreu de 11 a 14 de Março de 2009. Dos cerca de 420 participantes, 30\% dos 